\title{
Avaliação do ensino remoto emergencial de química: uma experiência na educação profissional
}

\author{
Evaluation of emergencial remote chemistry \\ teaching: an experience in professional education
}

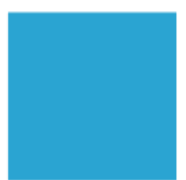

Revista Extensão em Foco
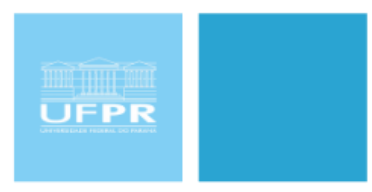

ISSN $\quad 2358-7180$

\author{
Patrícia Anselmo Zanotta ${ }^{1}$
}

\author{
RESUMO
}

\begin{abstract}
O ensino remoto emergencial tornou-se realidade para os cursos técnicos integrados ao ensino médio do campus Rio Grande do Instituto Federal de Educação, Ciência e Tecnologia do Rio Grande do Sul, a partir da suspensão das atividades presenciais, imposta pelo isolamento sanitário decorrente da pandemia da COVID-19. Apresenta-se nesse artigo, os textos produzidos no curso de extensão "Cirandar - 2020" que tratam de uma avaliação da experiência com o ensino de química nesse contexto, cujo objetivo é analisar os aspectos positivos e negativos, para que as estratégias de ensino possam ser reformuladas a partir desses resultados, de forma a se otimizar a permanência e êxito dos alunos nessa nova forma de ensino. A produção de informações se deu a partir de instrumentos de avaliação das atividades respondidos pelos alunos, de registros reflexivos feitos pela professora e de dados disponíveis no ambiente virtual de aprendizagem. A análise consistiu em interpretações estatísticas e qualitativas do conjunto de informações. Os principais resultados indicam a necessidade de um contínuo diálogo entre todos os envolvidos no processo, de aplicação de estratégias diversificadas, da realização de encontros síncronos esporádicos para a manutenção do vínculo, do estímulo para o desenvolvimento de trabalhos em grupos e da assunção de uma postura aberta às críticas. Conclui-se assim, que no contexto do ensino remoto emergencial, mais do que nunca, o professor precisa atuar como mediador das demandas e, os alunos como corresponsáveis pelas próprias aprendizagens num processo de interações dialógicas.
\end{abstract}

Palavras-chave: Ensino remoto emergencial. Estratégias didáticas. Ambiente virtual de aprendizagem.

\section{ABSTRACT}

Emergencial remote teaching became a reality for the high school integrated technical courses at Rio Grande campus of the Federal Institute of Education, Science and Technology of Rio Grande do Sul, since the suspension of in-person activities as a result of sanitary isolation due to COVID-19 pandemic. In this paper it is presented texts produced in the extension course "Cirandar - 2020" consisting in an evaluation of chemical teaching experience in this context, with the purpose of analyzing positive and negative aspects so that educating strategies can be reshaped from these results, in order to optimize students permanence and success in this new means of learning. The information production is based on activities assessment instruments answered by the students, on teacher's reflexive notes and on data provenient from the virtual learning environment. The analysis consisted in statistical and qualitative interpretation of the information set. The main results indicate the need for continuous dialogue between everyone involved in the process, implementation of diversified strategies, organizing sporadicus synchronous meetings for vinculum maintenance, encouragement for group projects development and to assume an open-minded stance for criticism. Thus it is concluded that in emergencial remote teaching context, more than ever, the teacher must act as a mediator of demands and the students as co-responsible for their own learning in a dialogical interaction process.

${ }^{1}$ Doutora em Educação em Ciências: Química da vida e saúde pela Universidade Federal do Rio Grande FURG. Docente EBTT no Instituto Federal de Educação, Ciência e Tecnologia do Rio Grande do Sul - IFRS, Rio Grande, RS, Brasil. E-mail: patricia.zanotta@riogrande.ifrs.edu.br. Orcid: https://orcid.org/0000-00032971-3226 
Keywords: Emergencial remote teaching. Educational strategies. Virtual learning environment.

\section{INTRODUÇÃO}

Apresenta-se no presente texto o conjunto das cartas produzidas durante o processo de formação do curso de extensão Cirandar - 2020. Nestas, tem-se o relato do contexto de ensino remoto emergencial do Instituto Federal de Educação, Ciência e Tecnologia do Rio Grande do Sul - IFRS e uma análise do experenciado por mim, enquanto professora de Química dos cursos técnicos integrados ao ensino médio de Automação Industrial e de Fabricação Mecânica do campus Rio Grande.

Na primeira carta faço a minha apresentação e a intenção inicial de pesquisa sobre o tema "a experimentação remota, assíncrona e investigativa", no contexto do início das Atividades Pedagógicas Não Presenciais - APNP. Já na segunda carta, é exposta uma visão mais realista de toda a situação vivenciada, da professora e dos alunos acostumados com o ensino presencial, terem que se adaptar ao ensino remoto sem a devida formação para tal, o que leva à mudança de foco na investigação da prática docente. Na terceira carta, é apresentada a primeira versão da pesquisa intitulada "as aprendizagens potencializadas através do ensino remoto emergencial" e a quarta carta refere-se a uma reescrita da anterior a partir da acolhida das sugestões recebidas através do processo de leitura entre pares oportunizado pelo Cirandar.

Para que esse texto não fique repetitivo, optei por não apresentar a terceira carta, pois muito dela está presente na quarta carta. Quero ainda destacar a colaboração da colega leitora a partir dos seus questionamentos, que num primeiro momento se colocou com empatia por experenciar uma situação semelhante, porém no contexto universitário, e, na sequência, auxiliou na diretividade do texto final.

Além da contribuição citada acima, as colegas da sala "Astromélia", como nomeamos nosso grupo no Cirandar, muito auxiliaram na condução do processo através das interações que ocorreram nos encontros síncronos. Faço esse destaque, pois nessa edição do projeto atuei também como coordenadora de sala, o que permitiu uma maior proximidade com os demais relatos e experiências, os quais de alguma forma impactaram nas minhas reflexões sobre o ensino remoto, como exposto nas cartas a seguir. 


\section{CARTA 1 - APRESENTAÇÃO E EXPECTATIVAS}

Rio Grande, 21 de setembro de 2020.

Querido(a)s Colegas,

Com muita alegria inicio a escrita da minha carta de apresentação, feliz por retornar ao Cirandar. No ano passado não consegui concluir o processo, foi a primeira vez que iniciei e não finalizei as escritas. Mas mesmo assim, nunca deixei de me sentir Cirandeira, nesse grupo tão acolhedor e que oportuniza nossa busca pelo conhecimento.

Esse ano é atípico para todos nós, e as possibilidades de caminhos para a pesquisa e o relato da prática são muitas, tudo é novo. Mas já tenho um foco, pelo menos por enquanto: A experimentação remota, assíncrona e investigativa.

Sou professora de Química do IFRS - Campus Rio Grande, e hoje iniciam nossas atividades pedagógicas não presenciais - APNP. A adesão a essas atividades foi facultada aos professores e alunos, e ocorrerão em três módulos mensais até o final do ano. O que ocorrerá após esse período é incerto, depende da prorrogação da Portaria 617 do MEC (MEC, 2020), que autoriza a substituição das aulas presenciais em cursos técnicos integrados ao ensino médio, por atividades não presenciais; e também da possibilidade ou não de retorno das atividades presenciais, além de questões próprias do Instituto.

Eu optei por ofertar os três módulos para as três disciplinas que ministro, são seis turmas ao todo. A adesão dos alunos no primeiro módulo foi bastante significativa, espero que consigamos atender as expectativas tanto deles como minhas, e que os próximos módulos continuem tendo uma boa procura.

Em minhas aulas presenciais trabalho bastante com a experimentação a partir dos princípios do Educar Pela Pesquisa (DEMO, 1997; GALIAZZI, 2014), mas como fazêlo no ensino remoto? Tenho buscado softwares de simulação de laboratório para contribuir no processo (LIMA, VARELO e NASCIMENTO, 2012; PASCOIN, CARVALHO e SOUTO, 2019; PASSOS et al, 2019 e PHET, 2020), mas a pesquisa em sala de aula é muito mais do que verificação/comprovação de resultados em experimentos. Então, hora de pesquisar. Toda sugestão é benvinda.

Forte Abraço,

Patrícia A. Zanotta 


\section{CARTA 2 - PERCEPÇÕES INICIAIS DO ENSINO REMOTO}

Rio Grande, 25 de outubro de 2020.

Queridas Colegas,

Inicio a escrita dessa segunda carta com muito menos certezas do que tinha no final da primeira carta. Passado um mês de oferta de atividades pedagógicas não presenciais - APNP do IFRS, me vejo envolta num turbilhão de tarefas para planejar, elaborar, corrigir, revisar, readequar, enfim, parece que não vou dar conta de tudo.

Em várias conversas com outros professores, inclusive pelos relatos das colegas de sala do Cirandar, vejo que a situação é semelhante para a maioria de nós, sendo que muitas ainda estão fazendo pós-graduação, possuem filhos pequenos, atendem familiares enfermos, etc. Mas não é oportuno compararmos nossos afazeres, e sim, buscar nos exemplos de superação, forças para enfrentar e superar os desafios que se apresentam.

Após esse breve desabafo, quero compartilhar que já não penso mais em estudar a experimentação no ensino remoto, não estou vendo como propor e nem como aprofundar os referenciais de tal pesquisa. Minha ideia agora é fazer um levantamento das aprendizagens oportunizadas durante esse processo de ensino remoto, tanto para os alunos, como para mim, enquanto professora.

Algo que já percebo, é que tenho tido mais contato com os alunos, me sinto mais próxima em alguns casos do que quando estávamos no ensino presencial. Parece que eles se sentem mais à vontade para expor suas dificuldades, e também compreendem que todos estamos aprendendo o fazer acadêmico remoto.

Os contatos com os alunos estão se dando tanto por e-mail, como por meio de avaliações no próprio moodle. E considero que essas respostas, objetivas e discursivas, possam servir de base para a realização da pesquisa. Além disso, tenho feito alguns registros das minhas percepções sobre o processo de APNP.

Forte Abraço,

Patrícia A. Zanotta 


\section{CARTA 4 - RELATO FINAL: ANÁLISE DO ENSINO DE QUÍMICA}

Rio Grande, 31 de março de 2021.

Olá colega cirandeiro(a),

Então chegou o momento de escrever a última carta, a partir do diálogo estabelecido com as sugestões da colega que fez a leitura do relato anterior e, de algumas proposições que haviam sido anunciadas. Inicialmente quero me apresentar, sou professora de Química, atuo nos cursos técnicos integrados ao ensino médio do campus Rio Grande do IFRS. E apresento como tema de estudo "as aprendizagens potencializadas através do ensino remoto emergencial". Com o uso do termo emergencial no título, já quero evidenciar que não sou professora EAD, apenas estou nessa situação de adaptação forçada ao ensino remoto, imposto pelo necessário distanciamento social iniciado no ano letivo de 2020 e, que provavelmente se estenderá por boa parte do ano de 2021.

Estruturei o relato para apresentar inicialmente como está ocorrendo o processo de Atividades Pedagógicas Não Presenciais - APNP no âmbito do campus Rio Grande, mais especificamente, para as disciplinas que ministro. Na sequência detalho algumas atividades propostas e como se deu a participação dos bolsistas do projeto de ensino "Formação integral pela experimentação em química" na escolha e elaboração das tarefas. Para o levantamento das aprendizagens oportunizadas durante esse processo de ensino remoto, tanto para os alunos, como para mim, enquanto professora, são utilizadas as respostas dos alunos às avaliações qualitativas de cada tarefa e dos módulos de uma forma geral, além dos meus diários reflexivos sobre as APNP. Por fim, concluo o relato com a síntese dos resultados e proposições para sequência e melhorias no processo de ensino e aprendizagem.

As aulas presenciais foram suspensas em março de 2020, e por um tempo ficamos sem orientações sobre retomada das atividades presenciais, implantação do ensino remoto ou cancelamento do calendário letivo. No início, ninguém imaginava que a pandemia duraria tanto tempo, que só poderemos pensar num possível retorno presencial quando todos estiverem vacinados, será que chegaremos nessa situação, em que toda a população estará imunizada? 
Nos primeiros meses de recesso, tentei manter o vínculo com os alunos, passando alguns materiais por e-mail, mas tive poucos retornos, a indefinição de prazos e como se daria a continuidade do ano letivo, auxiliou na inércia e apatia. Os mais preocupados eram os formandos, terá ENEM? Quando? Será usado para o SISU 2021? Quais universidades públicas irão ofertar vagas? E a formatura? Questões tão preciosas, que perderam um pouco da intensidade à medida que os casos de COVID-19 se tornaram próximos, que os óbitos não eram apenas números, mas nomes conhecidos.

Nesse turbilhão de sentimentos e experiências nunca pensadas, iniciou-se o ensino remoto em setembro de 2020. Cada professor teve autonomia para decidir se iria ou não ofertar suas disciplinas nessa modalidade, e os alunos puderam escolher em quais dessas iriam se inscrever. O calendário se manteve suspenso, essas atividades facultativas, poderão ser consideradas para aproveitamento de conteúdo e carga horária, mas quando o calendário for reiniciado, retomaremos às aulas como se fosse dia 16/03/2020. E como fica a situação dos alunos que participaram com aproveitamento das APNP? O que se decidiu foi que o professor assume o controle dos diversos andamentos na mesma turma. Ou seja, tem que controlar quem precisa realizar quais atividades, e dar conta de propor aulas para as diversas situações, de modo que um aluno não fique esperando até o momento em que os alunos que não participaram das APNP alcancem o mesmo estágio.

Uma situação quase impossível. Mas considerando que o ensino continuará de forma remota por mais um tempo, o que está ocorrendo é que os alunos que inicialmente puderam optar por não realizar as APNP (os motivos são diversos e muitos na verdade não “optaram”, mas realmente não tinham as mínimas condições de participar dessas atividades remotas), são agora obrigados a realizar tais atividades. E os professores estão ofertando novamente os módulos, aproveitando o que deu certo e modificando o que for necessário.

Focando nas disciplinas que ministro: ofertei as três químicas (geral para o segundo ano, físico-química para o terceiro e orgânica para o quarto ano) para os cursos de Automação Industrial (turmas identificadas pela letra "E”) e Fabricação Mecânica ("F"), nos três módulos mensais que ocorreram entre setembro e dezembro de 2020, correspondentes ao ciclo 1. E também, nos três módulos do ciclo 2, realizado entre janeiro a abril de 2021. A carga horária de cada módulo ficou limitada ao equivalente presencial para cada período, ou seja, foram consideradas apenas $8 \mathrm{~h}$ para cada período de 4 semanas, foi feita uma relação direta entre o tempo de sala de aula presencial e o ensino remoto. 
Considero essa uma grave falha e prejuízo aos alunos, pois mesmo que a atual situação não seja análoga à educação a distância regular, o cômputo no ensino remoto não deve ser idêntico ao presencial, pois é preciso considerar o tempo efetivo dedicado pelos alunos, uma vez que as atividades são em grande maioria assíncronas.

Este é um dos pontos que considero ser necessário buscar respaldo em referenciais que auxiliem na compreensão do que estamos fazendo afinal. Cito o posicionamento de FLORES e LIMA (2021) que apresentam o ensino remoto emergencial como algo entre o ensino presencial e a educação a distância:

Esse ensino emergencial, dado à força das circunstâncias, não forneceu uma educação online de qualidade, procurando apenas oportunizar um acesso rápido e emergencial à matéria. É, portanto, passível de fragilidades, pois é um modelo educacional concebido na emergência, estabelecido sem a reflexão necessária. FLORES e LIMA (2021)

Esse excerto conforta em parte as angústias em relação a se estar fazendo o mais correto, o melhor para os alunos. Estamos na verdade, tentando. Acertando as vezes, errando, refletindo, avaliando, enfim, aprendendo fazer, fazendo. Um importante aliado nesse processo são os instrumentos utilizados para avaliação qualitativa, respondido pelos alunos sempre ao final de cada módulo, e cujas informações geradas são discutidas em detalhes mais adiante.

Um dos resultados dessas reflexões ao longo do processo, foi a viabilidade de oferta de um estudo dirigido preparatório para a Olimpíada de Química do Rio Grande do Sul OQRS, como um componente extra no ambiente virtual, com adesão facultativa aos interessados, e possibilidade de aproveitamento da correspondente carga horária para complementar a carga das disciplinas curriculares. Do mesmo modo, uma regulamentação interna do IFRS oportunizou que o último módulo dos componentes dos quartos anos, pudessem ter suas cargas elevadas em relação à carga presencial, de modo a acelerar a conclusão do componente curricular para os formandos (IFRS, 2021).

Apresento na sequência alguns dados referentes à participação e aproveitamento dos alunos nas APNP. As seis turmas tiveram uma boa adesão inicial por parte dos alunos (todas acima de 70\%), como pode ser visto no Gráfico 1, onde são apresentados os percentuais de alunos inscritos em cada módulo, sempre em relação ao número total de alunos matriculados no início do ano letivo de 2020. Em todas as turmas, houve uma 
queda na participação nos três primeiros módulos (indicados por M1, M2 e M3), contudo, houve um aumento na procura no início do segundo ciclo (etapa M4), talvez em função da iminente retomada do calendário com uma possível obrigatoriedade na realização das APNP. Excetua-se apenas a turma 3F, que manteve a queda na participação dos alunos e atingiu uma "evasão" no módulo 4 de 63,6\% dos alunos. Contudo, esse otimismo não se manteve, e novamente houve queda na participação nos demais módulos do ciclo 2 .

Gráfico 1 - Participação dos alunos nas aulas remotas de Química

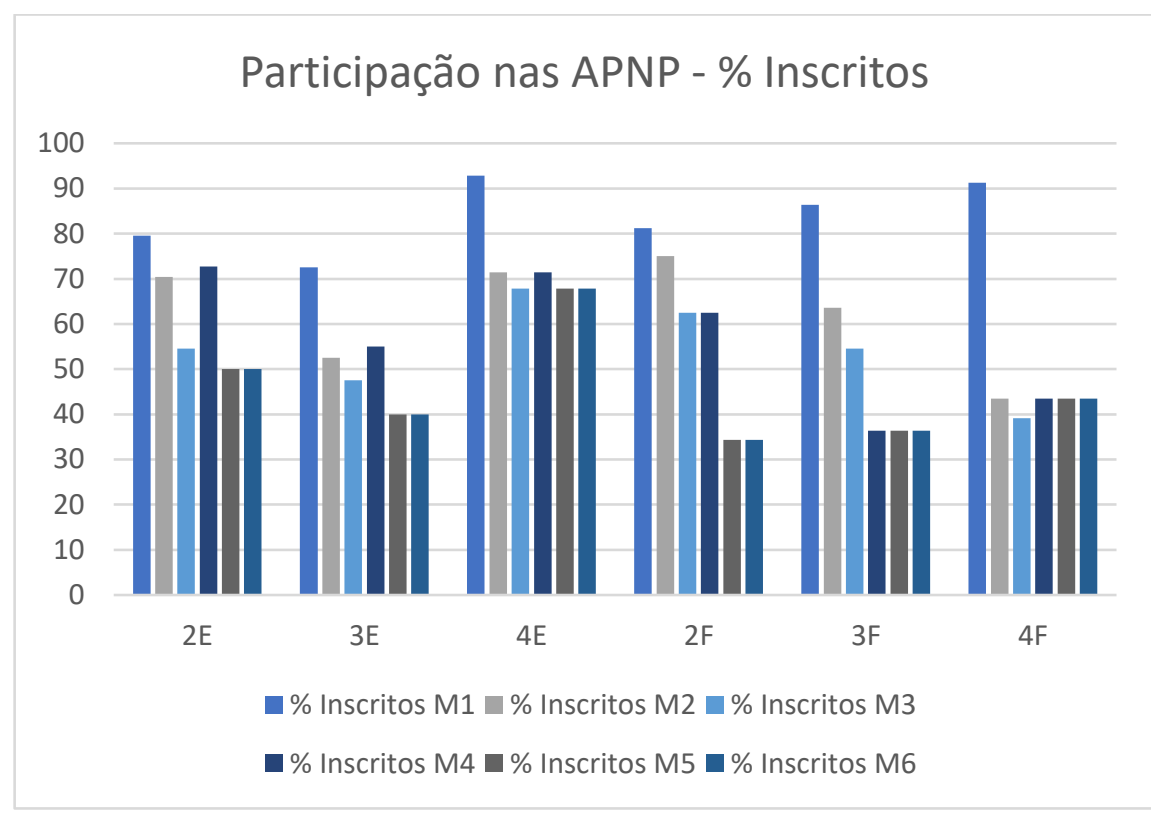

Fonte: Autoria própria.

Além da inscrição nos módulos, verificou-se também o percentual de alunos participantes que obtiveram aproveitamento em cada etapa. Sendo considerado para tanto os alunos que obtiveram pelo menos média sete. Os resultados são apresentados no Gráfico 2.

Na grande maioria dos casos, o não aproveitamento do módulo se deu por abandono e não realização das tarefas, uma vez que foram oportunizadas diversas formas de recuperação ao longo de cada módulo. Em algumas raras situações, os alunos chegaram a realizar os trabalhos, mas não fizeram as correções solicitadas e por isso ficaram abaixo da média necessária para aprovação. Corrobora com essa constatação o fato de $75 \%$ dos alunos alegarem que não utilizaram os atendimentos síncronos pois não acharam 
necessário, demonstrando que não houve muito interesse em sanar as dúvidas diretamente com a professora.

Gráfico 2 - Aproveitamento dos alunos no ensino remoto de Química

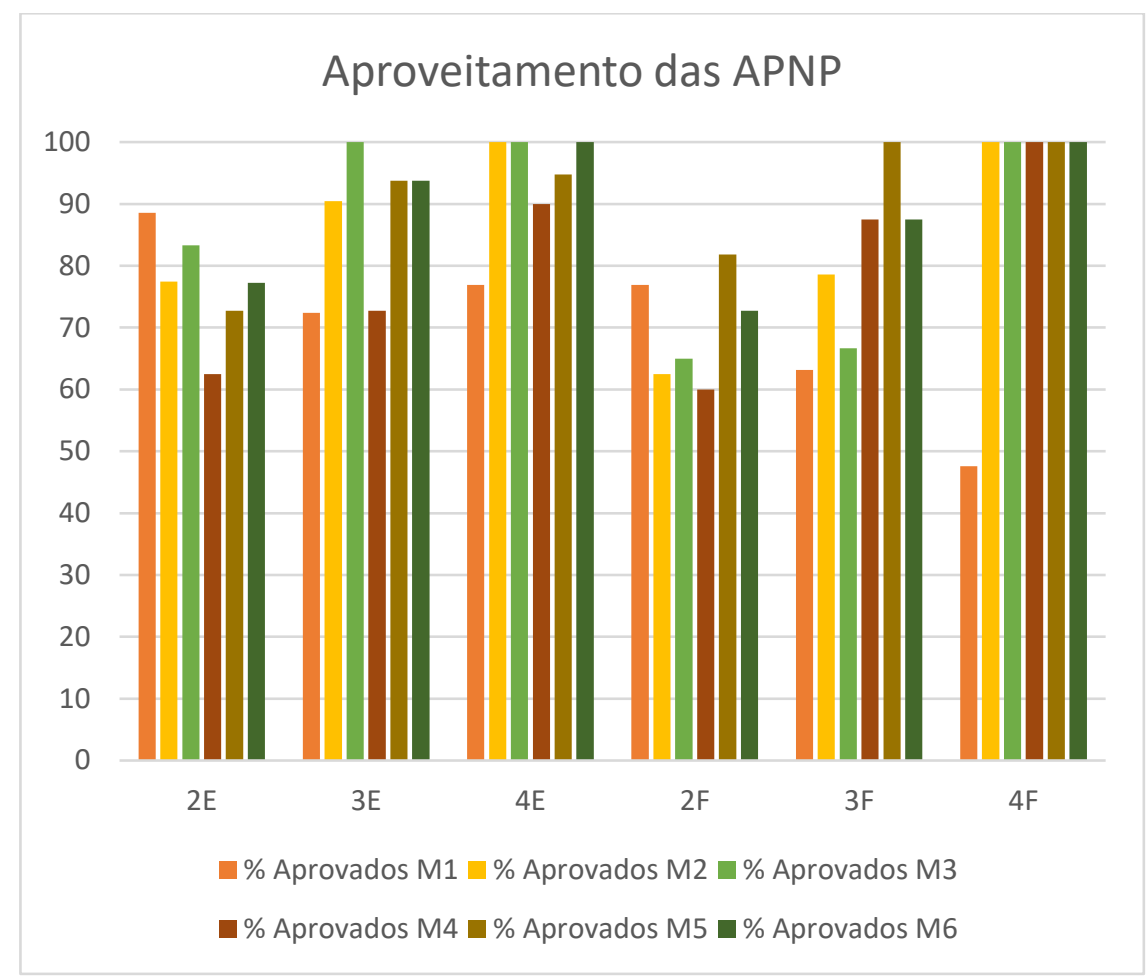

Fonte: Autoria própria.

A análise dos dados da turma 4F evidencia o baixo aproveitamento no módulo 1 em razão da desistência, pois os alunos que concluíram o primeiro módulo foram os mesmos que efetivamente participaram dos demais módulos, nos quais a turma teve $100 \%$ de aprovação. Para as demais turmas, é possível observar um aumento no aproveitamento entre os módulos 4 e 6 , o que provavelmente se justifica pela expectativa de retomada do calendário e aproveitamento de conteúdos e cargas desenvolvidos como APNP.

No Gráfico 3 apresenta-se uma síntese do aproveitamento global de cada turma em relação ao número total de alunos matriculados no sistema acadêmico (SIA), ao número total de alunos inscritos em pelo menos um módulo das APNP, e também referente ao número de alunos que efetivamente participaram das atividades em pelo menos um módulo. Destaca-se o percentual de aprovação dos alunos ativos nas APNP, de pelo menos $87 \%$ para cada turma, o que evidencia a eficiência das atividades desenvolvidas, e o resultado de $64 \%$ de aproveitamento integral da disciplina de Química III para os 
alunos regularmente matriculados na turma $4 \mathrm{E}$, demonstrando o engajamento dos formandos do curso de Automação Industrial.

Gráfico 3 - Aprovação global dos alunos nas aulas remotas de Química

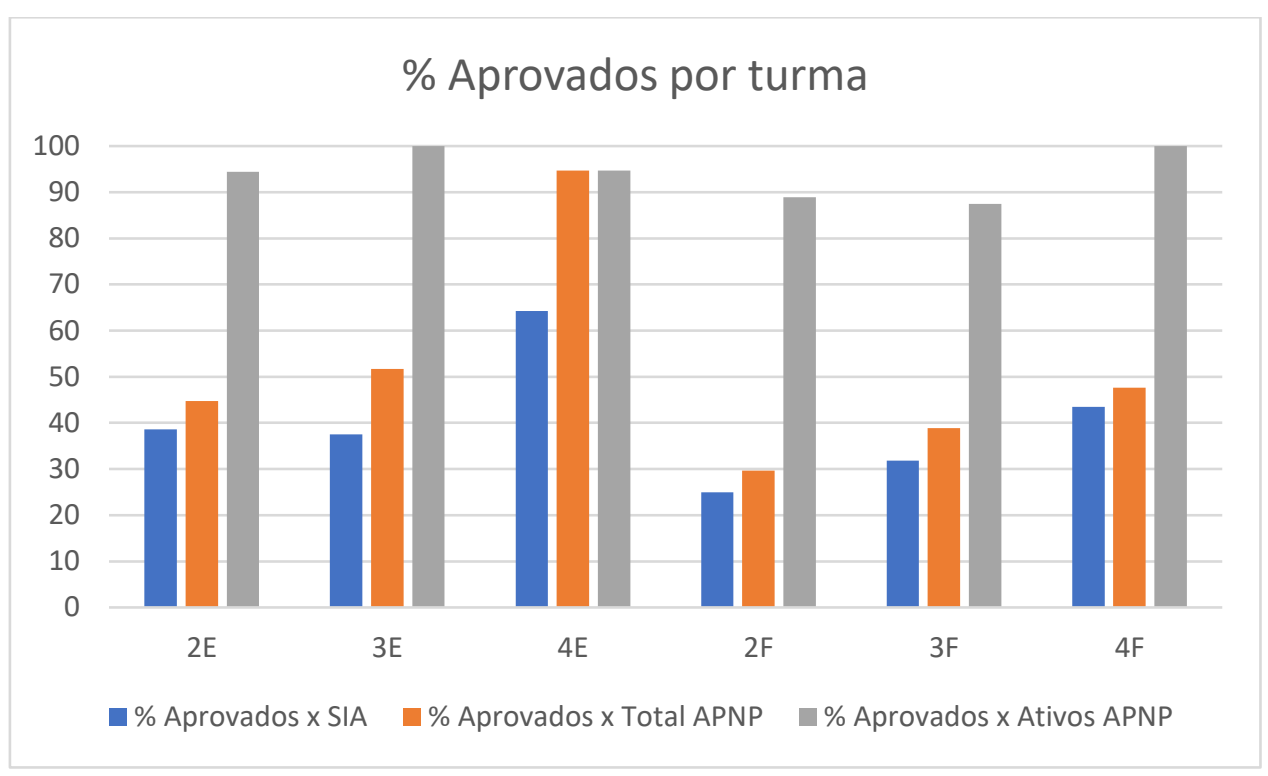

Fonte: Autoria própria.

Foram feitas tentativas de contato com os alunos desistentes para entender seus motivos e, se possível intervir para que retornassem. Poucos deram retorno, e dentre as justificativas para a "evasão" do ensino remoto não obrigatório, citaram problemas familiares, como doenças de parentes (COVID-19 inclusive), necessidade de auxiliar a família em afazeres domésticos ou pequenos negócios; falta de condições materiais como computadores, acesso precário à internet e inexistência de espaço reservado para concentração nos estudos; interesse na esperada conclusão do ensino médio (que em função do calendário suspenso era uma incógnita) buscando o ENCEEJA para então tentar uma vaga no ensino superior pelo SISU e; inadaptação ao modelo de ensino, especialmente no que tange à responsabilidade pela própria aprendizagem.

Nas disciplinas de química foram propostas atividades diversas, como mapas mentais, glossários coletivos, questionários no próprio moodle, trabalhos de pesquisa, simuladores e experimentos práticos para realização pelos alunos em suas casas. Em todos as situações foram solicitadas avaliações qualitativas das propostas, para que os alunos manifestassem suas opiniões sobre o desenvolvimento dos módulos e assim, fosse possível realizar mudanças nos módulos seguintes. 
Além dessas avaliações, os bolsistas do projeto de ensino "Formação integral pela experimentação em química" contribuíram de forma inestimável para as APNP. Os mesmos atuaram de forma independente nas três disciplinas, sendo dois bolsistas em Química III, uma bolsista em Química II e duas bolsistas em Química I. Entre suas tarefas, estava a busca por recursos didáticos alternativos aos disponíveis no moodle, como o simulador da determinação da concentração de ácido acético no vinagre por meio de uma titulação ácido/base, calculadora do teor calórico dos alimentos com detalhamento dos teores de carboidratos, proteínas e lipídeos em cada porção, simuladores de célula galvânica e de pilhas no estudo da eletroquímica, construção simulada de um átomo e de uma molécula, e proposição de experimentos práticos que pudessem ser realizados com materiais caseiros.

Os bolsistas testavam os recursos procurando identificar possíveis dificuldades que os alunos iriam encontrar e elaboravam tutoriais de uso dos mesmos. Outra importante contribuição das bolsistas foi que algumas eram alunas das disciplinas nas quais as atividades estavam sendo desenvolvidas e tinham uma visão também como aluno que deveria realizar a atividade de forma avaliada. Além disso, o contato direto com os colegas oportunizava uma avaliação mais intensa da aceitação e dificuldades de cada recurso proposto.

Os resultados das avaliações qualitativas, evidenciaram a grande aceitação das simulações e solicitação dos alunos para que recursos semelhantes continuassem sendo empregados tanto nas APNP como no ensino remoto após a retomada do calendário letivo. Com algumas exceções, como as turmas $2 \mathrm{E}$ e $4 \mathrm{~F}$, que preferiram realizar o experimento prático ao uso dos simuladores, conforme evidenciado no Gráfico 4.

Destaca-se ainda o comportamento distinto entre as turmas de Química 1, para as quais foram propostas as mesmas tarefas. No curso de Automação Industrial 78\% dos alunos optaram pelo trabalho experimental, enquanto na turma de Fabricação Mecânica todos os alunos realizaram a atividade simulada. A motivação para tais comportamentos precisa ainda ser melhor compreendida. 
Gráfico 4 - Preferência por atividades práticas caseiras ou simuladores

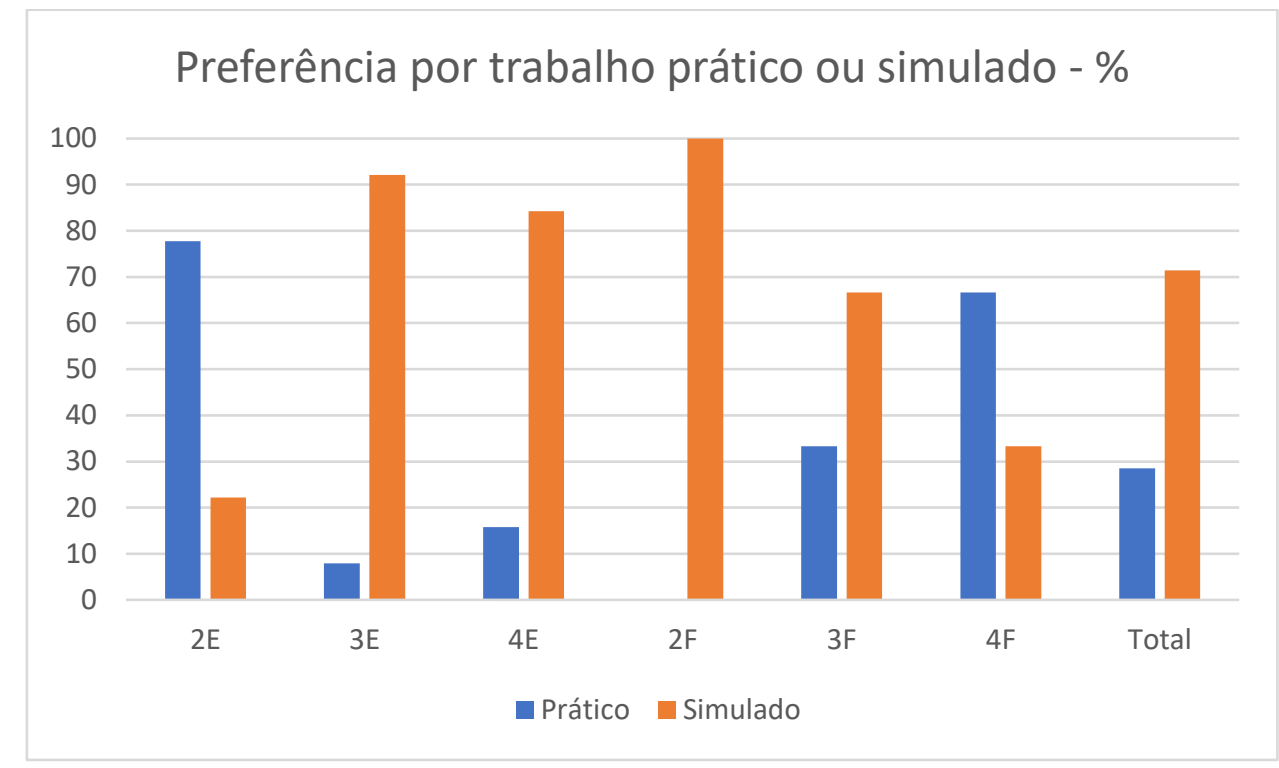

Fonte: Autoria própria.

Outro ponto que foi evidenciado nas respostas dos alunos trata da necessidade de aprender a organizar o tempo de estudo. No módulo III as tarefas foram apresentadas no início do módulo, mas o prazo máximo de entrega ficou para a última semana. Vários alunos solicitaram que os prazos voltassem a ser em períodos menores, pois o fato de ficar no final, fez com que se perdessem e deixassem tudo para o mesmo período. Abaixo são apresentadas algumas falas que corroboram essa observação.

Eu não gostei do fato que todas as tarefas estavam marcadas para o mesmo dia, e como eu faço as tarefas em ordem cronológica acabou ficando muito ruim para mim, além das tarefas de química tinham outras que também estavam marcadas para o mesmo dia. (Aluno1)

Não gostei da distribuição de provas e trabalhos durante o módulo. (Aluno 2)

Eu sigo o que eu tenho que fazer pelos avisos de data de entrega, que antes na sua matéria eram semanais e agora não foram, e isso me fez esquecer totalmente que eu tinha matéria de química kkkk. Poderias por os avisos de entrega só para "marcar" os dias em que se recomenta fazer as matérias? como por exemplo no primeiro ciclo, que a cada 4 ou 5 dias tinha um aviso em que se tinha que estudar aquela parte da matéria. Isso ajuda em muito a me organizar a estudar. Agradeço desde já. (Aluno 3)

Não gostei das atividades só no final, em vez de separadas semanalmente. (Aluno 4)

A questão "Dentre as avaliações propostas, você teve dificuldade em:" com alternativas específicas para cada disciplina e cada módulo, teve grande manifestações de dificuldades em utilizar planilha eletrônica e responder os questionários, especialmente 
quando todo o conteúdo do módulo foi concentrado em um único instrumento ao final da respectiva etapa. Houve também algumas manifestações de incômodo em utilizar os glossários e fóruns coletivos das turmas, pois as respostas eram públicas para os demais colegas, e isto os deixavam expostos.

Com relação à quantidade de conteúdos trabalhados no módulo, em que as alternativas eram: 1. Foi adequada para a duração do módulo; 2. Foi adequada para a duração do módulo, mas mal distribuída entre as semanas; 3. Foi pouca para a carga horária total do módulo; 4. Houve sobrecarga de conteúdos. Os resultados apresentados no Gráfico 5, em que são informados os percentuais de alunos que consideraram a quantidade de conteúdo adequada para a duração do módulo, mostram um baixo desempenho nesse quesito especialmente para o primeiro módulo de Química II, e ainda que para a turma 3F, somente os dois últimos módulos tiveram uma boa distribuição.

Gráfico 5 - Adequação da quantidade de conteúdo por turma

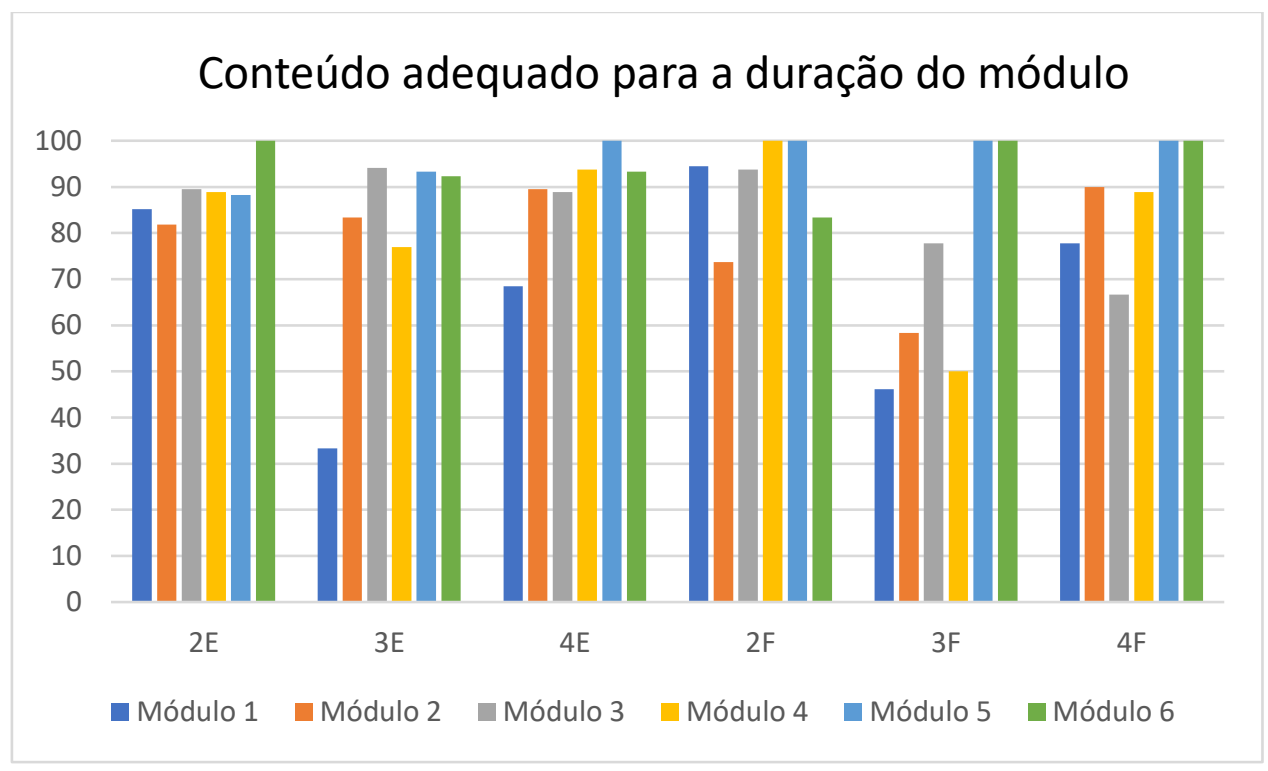

Fonte: Autoria própria.

Contudo, ao se analisar o Gráfico 6, em que são apresentadas as médias entre as seis turmas, por módulo, se verifica que houve uma melhora na adequação da quantidade de conteúdos com o passar do tempo, e com as experiências do ensino remoto. Tanto que a partir do terceiro módulo, pelo menos $80 \%$ dos alunos consideraram adequada e nos dois últimos módulos o percentual de concordância foi superior a 95\%. Acredita-se que a pequena queda no valor do terceiro para o quarto módulo, seja consequência da adesão 
de novos alunos no segundo ciclo, os quais não haviam participado da primeira etapa das APNP.

Gráfico 6 - Adequação da quantidade de conteúdo por módulo

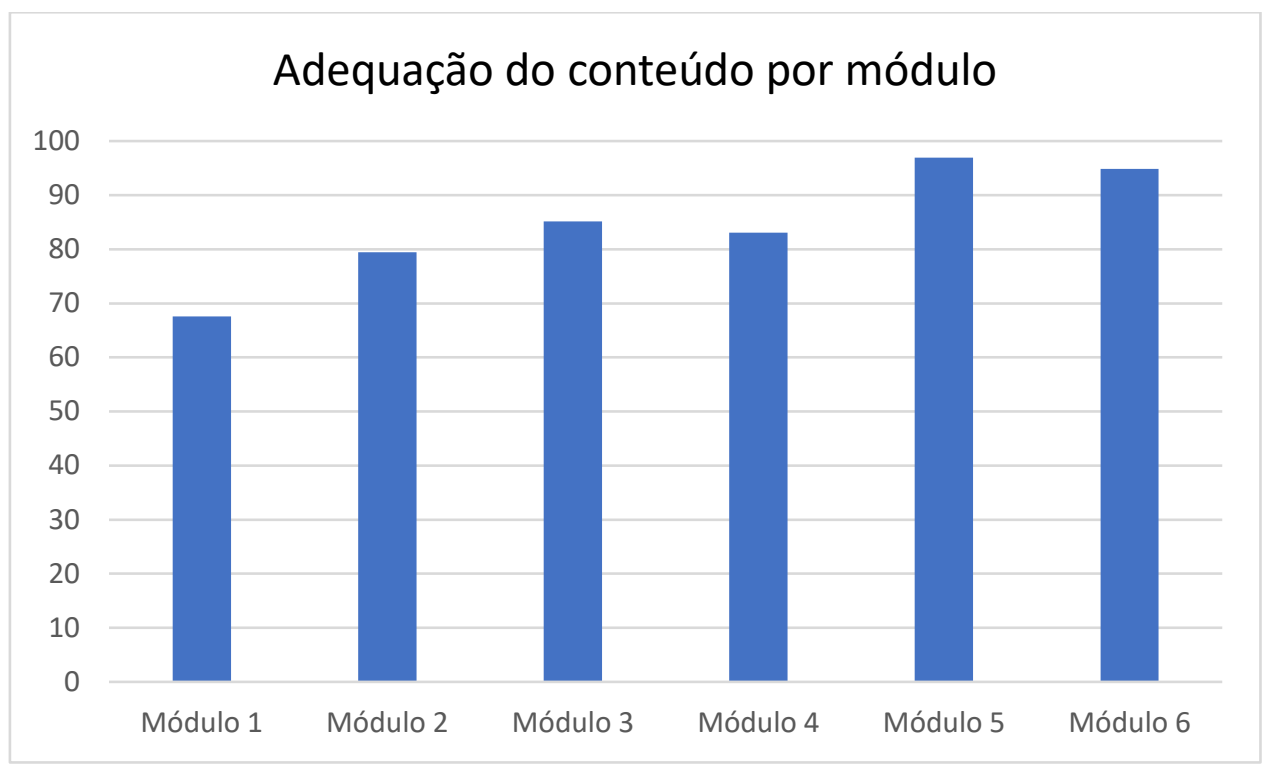

Fonte: Autoria própria.

Durante todo o período das APNP houve baixa solicitação de atendimentos síncronos pelos alunos, sendo a justificativa de $75 \%$ dos alunos, o fato de não terem solicitado pois não acharam necessário. Além desses encontros, as dúvidas eram sanadas através do próprio ambiente virtual e principalmente por comunicação por e-mail entre alunos e professora.

Em abril de 2021 encerraremos o último módulo de APNP e iniciaremos a retomada do calendário letivo de 2020 para as turmas de formandos do ensino técnico integrado. Para as demais turmas, o calendário será reiniciado em maio. Por todos os resultados aqui apresentados, e pelos depoimentos informais dos alunos, finalizo esta etapa com o sentimento de dever cumprido. Muitas coisas poderiam ter sido propostas de forma diferente, e espero usar estas avaliações para fazer ajustes no ensino remoto que será desenvolvido a partir de agora.

Além de assumir essa proposição para a minha prática docente, ensejo organizar o tempo de trabalho para efetivar as tantas escritas que gostaria de fazer. Muitas experiências interessantes foram desenvolvidas nesse ano tão atípico, e precisam ser compartilhadas. Por isso, convido você leitor, a também se desafiar a compartir suas 
vivências. Que a rede de educadores se fortaleça cada vez mais e que tenhamos no coletivo o apoio necessário para seguirmos em frente.

Abraços,

Patrícia Anselmo Zanotta

\section{SÍNTESE DOS RESULTADOS}

O calendário acadêmico foi finalmente retomado no IFRS, em vinte e seis de abril de 2021 para as turmas de formandos do integrado, e em dezessete de maio para as demais turmas. O primeiro grupo teve suas inscrições no ambiente virtual de aprendizagem AVA feitas pela direção de ensino, devido ao pouco tempo entre o final das APNP e o início das aulas, enquanto para as outras turmas, cada aluno deveria fazer sua própria inscrição, como forma de se ter um levantamento de quantos alunos pretendiam participar efetivamente das atividades escolares.

Ao se analisar os acessos ao AVA das turmas de química, é possível estimar o percentual de evasão dos alunos, conforme exposto no Gráfico 7. Em todos os casos, a desistência é inferior a $20 \%$ e nula para a turma 4F. Um cenário distinto do que foi observado em relação à não adesão nas APNP, que chegou a ser de $65 \%$ para a turma $2 \mathrm{~F}$ nos dois últimos módulos.

Gráfico 7 - Alunos inativos no AVA x Matriculados no SIA

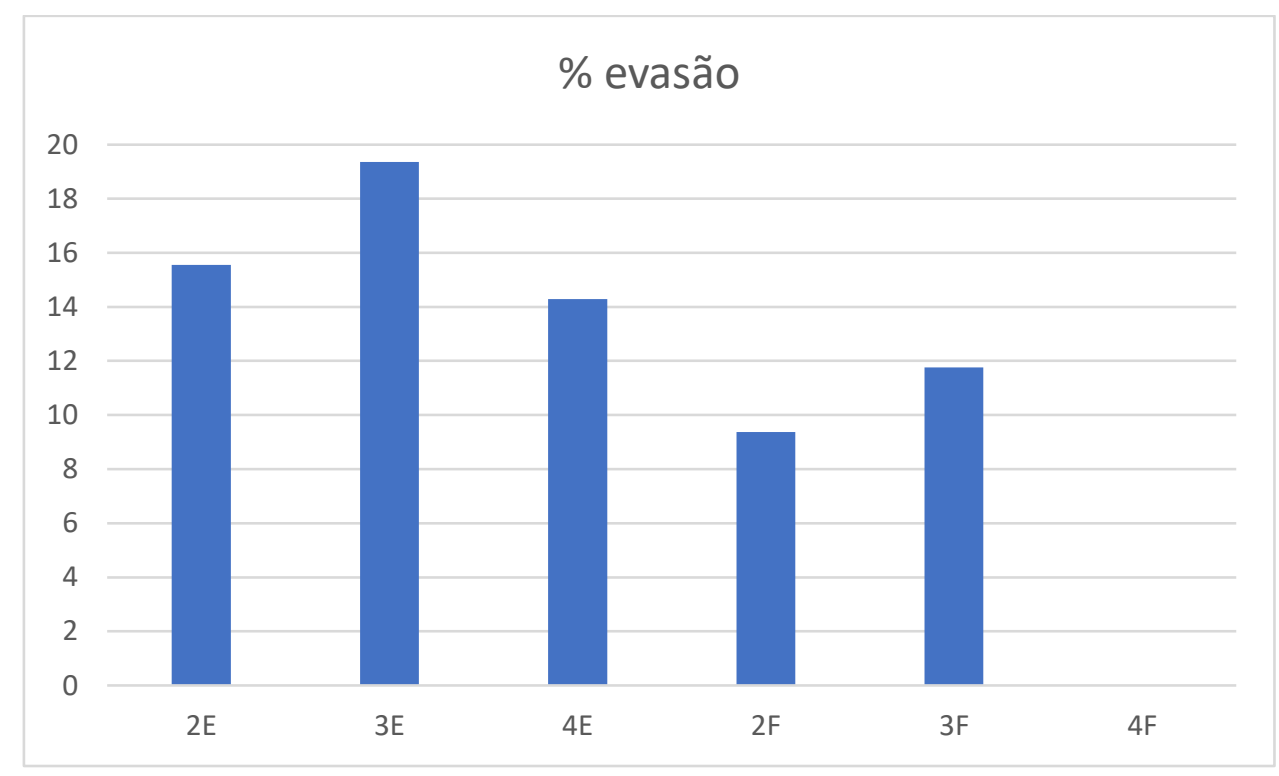


Fonte: Autoria própria.

Esses dados são muito significativos, pois na cidade do Rio Grande, todas as demais escolas concluíram o ano letivo de 2020 no máximo até abril de 2021, porém no IFRS o ano letivo dos formandos encerrará em setembro e o das outras turmas somente encerrará em dezembro de 2021, ou seja, com um ano de defasagem em relação ao contexto pré-pandêmico. Alguns alunos se inscreveram no ENCCEJA paralelamente ao curso técnico, como forma de garantir a conclusão do ensino médio num espaço de tempo menor, essa alternativa não se mostrou muito eficiente nesse quesito, uma vez que a sua realização foi adiada para o segundo semestre do ano. Assim, como terceira via, vários alunos estão buscando a certificação através do NEEJA, e estão tendo sucesso. Porém, apesar de terem finalizado o ensino médio, desejam concluir o curso técnico integrado, e por isso, permanecem participando das atividades remotas.

Contudo, deve-se analisar esse cenário para além do otimismo e da crença de que os alunos irão permanecer no curso através do ensino remoto emergencial, pois no início da oferta das APNP a taxa de adesão também foi alta, e logo depois ocorreu uma desistência significativa. É preciso um esforço de todos os envolvidos para compreender os diversos fatores que levaram à evasão das APNP para que o processo não se repita no atual contexto.

\section{CONSIDERAÇÕES FINAIS}

Ao longo do texto foram apresentados vários dados que buscaram identificar aspectos positivos e negativos da experiência com o ensino remoto emergencial de química. Além disso, foi exposta a situação de adesão dos alunos quanto à retomada do calendário acadêmico e a necessidade do desenvolvimento de ações planejadas e embasadas no vivenciado nas APNP.

Assim, como forma de contribuir para a reflexão e proposição de estratégias para a permanência e o êxito dos alunos, destaco as principais considerações elencadas a partir da análise do processo experenciado no ensino remoto emergencial de química, em cursos técnicos integrados ao ensino médio no IFRS: 
a) realizar periodicamente avaliações qualitativas para oportunizar que os alunos indiquem o que está funcionando e o que pode ser modificado;

b) avaliar a quantidade de conteúdo e sua distribuição ao longo dos bimestres;

c) propor atividades bastante diversificadas, cada aluno tem suas preferências, não é possível agradar a todos, então podemos buscar que o ensino não seja monótono;

d) realizar alguns encontros síncronos (não em demasia), auxilia na manutenção do vínculo e aproxima os atores do processo;

e) permitir a realização de trabalhos em grupos, as interações entre os alunos auxiliam no processo de aprendizagem, e a redução no número de atividades a serem corrigidas facilita o trabalho dos professores;

f) assumir que a situação é emergencial, que erros serão cometidos e, portanto, é preciso estar aberto a críticas e a autorreflexão.

Os itens citados acima não intencionam ser soluções, são apenas uma síntese do que observei na minha experiência com o ensino remoto emergencial e a partir dos quais novas estratégias estão sendo planejadas. Destaco como principal reflexão e assunção de postura enquanto professora, que me vejo cada vez mais como mediadora do processo, é necessário oportunizar ferramentas diversificadas, mas especialmente no contexto do ensino remoto, os alunos precisam assumir seus papeis como autores da própria aprendizagem.

\section{REFERÊNCIAS}

BRASIL, MEC. Portaria $\mathbf{n}^{\mathbf{0}}$ 617, de 3 de agosto de 2020. Disponível em: <https://www.in.gov.br/en/web/dou/-/portaria-n-617-de-3-de-agosto-de-2020270223844>. Acesso em: 15 ago. 2020.

DEMO, P. Educar pela Pesquisa. 2 ed. Campinas: Autores Associados, 1997.

FLORES, J.; LIMA, V. Educação em tempos de pandemia: dificuldades e oportunidades para os professores de ciências e matemática da educação básica na rede pública do Rio Grande do Sul. Revista Insignare Scientia - RIS, v. 4, n. 3, p. 94-109, 3 mar. 2021. 
GALIAZZI, M.C. Educar pela pesquisa: ambiente de formação de professores de ciências. Ijuí: Ed. Unijuí, 2014.

IFRS. CONSUP: Resolução $\mathrm{N}^{\circ}$ 015/2021, 2021. Disponível em: $<$ https://ifrs.edu.br/wpcontent/uploads/2021/02/Resolucao_015_2021_Aprova_retomada_calendario_academi co.doc.pdf>. Acesso em 25 abr. 2021.

LIMA, M.A.; VARELO, M.F.F.; NASCIMENTO, A.Q. O uso de simuladores virtuais para o ensino de Química. VII CONNEPI, Palmas, 2012. Disponível em: http://propi.ifto.edu.br/ocs/index.php/connepi/vii/paper/view/2641/230. Acesso em: 24 ago. 2020.

PASCOIN, A.F.; CARVALHO, J.W.P.; SOUTO, D.L.P. Ensino de química orgânica com o uso dos objetos de aprendizagem ATOMLIG e simulador construtor de moléculas. Revista Signos, Lajeado, ano 40, n. 2, p. 208-226, 2019. Disponível em: <http://www.univates.br/revistas/index.php/signos/article/view/2334/1574>. Acesso em: 20 ago. 2020.

PASSOS, I.N.G.; SOUSA, J.L.S.; SOUSA, S.F.; LEAL, R.C. Utilização do software PhET no ensino de Química em uma escola pública de Grajaú, Maranhão. Revista Observatório, vol. 5, n. 3, maio 2019. Disponível em: <https://sistemas.uft.edu.br/periodicos/index.php/observatorio/article/view/4626/15353 >. Acesso em: 24 ago. 2020.

PHET. Simulações de química. Disponível em: <https://phet.colorado.edu/pt_BR/simulations/filter?subjects=chemistry\&sort=alpha\&vi ew=grid >. Acesso em: 27 ago. 2020.

Recebido em: 21 de maio de 2021. Aceito em: 26 de maio de 2021. 